\title{
Technical note: drifting versus anchored flux chambers for measuring greenhouse gas emissions from running waters
}

\author{
A. Lorke ${ }^{1}$, P. Bodmer ${ }^{2,3}$, C. Noss ${ }^{1}$, Z. Alshboul ${ }^{1}$, M. Koschorreck ${ }^{4}$, C. Somlai-Haase ${ }^{1}$, D. Bastviken ${ }^{5}$, S. Flury ${ }^{2}$, \\ D. F. McGinnis ${ }^{2,6}$, A. Maeck ${ }^{7}$, D. Müller ${ }^{8,9}$, and K. Premke ${ }^{2,10}$ \\ ${ }^{1}$ Institute for Environmental Sciences, University of Koblenz-Landau, Fortstr. 7, 76829 Landau, Germany \\ ${ }^{2}$ Leibniz-Institute of Freshwater Ecology and Inland Fisheries, Chemical Analytics and Biogeochemistry, \\ Müggelseedamm 310, 12587 Berlin, Germany \\ ${ }^{3}$ Institute of Biology, Freie Universität Berlin, 14195 Berlin, Germany \\ ${ }^{4}$ Helmholtz Centre for Environmental Research - UFZ, Department Lake Research, Brückstr. 3a, 39114 Magdeburg, \\ Germany \\ ${ }^{5}$ Linköping University, Department of Thematic Studies - Environmental Change, 58183 Linköping, Sweden \\ ${ }^{6}$ Institute F.-A. Forel, Section of Earth and Environmental Sciences, University of Geneva, Geneva, Switzerland \\ ${ }^{7}$ Senect GmbH \& Co. KG, An 44 - No. 11, 76829 Landau, Germany \\ ${ }^{8}$ Institute of Environmental Physics (IUP), Otto-Hahn-Allee 1, 28359 Bremen, Germany \\ ${ }^{9}$ Center for Tropical Marine Ecology (ZMT), Fahrenheitsstr. 8, 28359 Bremen, Germany \\ ${ }^{10}$ Leibniz Centre for Agricultural Landscape Research, Institute for Landscape Biogeochemistry, \\ Eberswalder Straße 84, 15374 Müncheberg, Germany
}

Correspondence to: A. Lorke (lorke@uni-landau.de)

Received: 1 August 2015 - Published in Biogeosciences Discuss.: 4 September 2015

Revised: 19 November 2015 - Accepted: 21 November 2015 - Published: 7 December 2015

\begin{abstract}
Stream networks have recently been discovered to be major but poorly constrained natural greenhouse gas (GHG) sources. A fundamental problem is that several measurement approaches have been used without crosscomparisons. Flux chambers represent a potentially powerful methodological approach if robust and reliable ways to use chambers on running water can be defined. Here we compare the use of anchored and freely drifting chambers on various streams with different flow velocities. The study clearly shows that (1) anchored chambers enhance turbulence under the chambers and thus elevate fluxes, (2) drifting chambers have a very small impact on the water turbulence under the chamber and thus generate more reliable fluxes, (3) the bias of the anchored chambers greatly depends on chamber design and sampling conditions, and (4) there is a promising method to reduce the bias from anchored chambers by using a flexible plastic foil collar to seal the chambers to the water surface, rather than having rigid chamber walls penetrating into the water. Altogether, these results provide novel guidance on how to apply flux chambers in running water, which
\end{abstract}

will have important consequences for measurements to constrain the global GHG balances.

\section{Introduction}

Rivers and streams have been identified as important links in the global carbon cycle. They receive and transport terrestrial carbon from the land to the ocean and are also shown to be a net source of greenhouse gases (GHG), i.e., carbon dioxide $\left(\mathrm{CO}_{2}\right)$ and methane $\left(\mathrm{CH}_{4}\right)$ (Aufdenkampe et al., 2011; Battin et al., 2008; Cole et al., 2007; Tranvik et al., 2009). In a recent study, the global $\mathrm{CO}_{2}$ emissions from rivers and streams were estimated to be $1.8 \pm 0.25 \mathrm{Gt} \mathrm{C}_{\text {year }}{ }^{-1}$ (Raymond et al., 2013), which corresponds to $70 \%$ of the global ocean carbon sink (Le Quéré et al., 2014). Due to the lack of knowledge of surface area and gas exchange velocity, the smallest streams are considered to be a major unknown component of regional- to global-scale GHG emission estimates (Bastviken et al., 2011; Cole et al., 2007). Despite these knowledge gaps, 
there are strong indications that small streams have the highest gas exchange velocities (Aufdenkampe et al., 2011), highest $\mathrm{CO}_{2}$ partial pressures (Koprivnjak et al., 2010) and cover the largest fractional surface area within fluvial networks (Butman and Raymond, 2011). A continental-scale analysis of $\mathrm{CO}_{2}$ efflux from streams and rivers revealed a continuous decline of the fluxes with increasing size and discharge of the aquatic systems (Hotchkiss et al., 2015).

Ecosystem-scale fluxes of $\mathrm{CO}_{2}$ and $\mathrm{CH}_{4}$ from running waters are often derived indirectly using measured gas partial pressure in the surface water in combination with estimates of a gas exchange velocity. For sparingly soluble gases, the exchange velocity is mainly controlled by turbulence at the water-side of the air-water interface. In smaller rivers and streams, turbulence is driven by stream velocity, depth, and bottom roughness (Marion et al., 2014), and the resulting gas exchange velocities are often parameterized with one or more of the following terms: stream order, slope, flow velocity, discharge, width, and depth (Alin et al., 2011; Raymond et al., 2012; Wallin et al., 2011). In small streams, reachscale estimates of the gas exchange velocity can also be derived from gas tracer experiments, whereby a volatile tracer (e.g., propane or sulfur hexafluoride) is injected upstream and the longitudinal decrease of its dissolved concentration is measured (Halbedel and Koschorreck, 2013; Raymond et al., 2012). For practical reasons, tracer gas injections are limited to application in small streams and alternative methods suitable for a greater range of stream sizes are needed. Moreover, recent studies have suggested that the gas exchange velocity of $\mathrm{CH}_{4}$ can be enhanced by microbubbles (Beaulieu et al., 2012) and can therefore differ from that of the volatile tracer. To better constrain ecosystem-scale estimates of GHG emissions and to improve the understanding of the flux drivers in small running waters, reliable methods are required that allow direct measurements.

As eddy-covariance (Baldocchi, 2014) measurements are not suitable for small streams, gas flux chambers that float on the water surface are a straightforward and inexpensive method for direct measurements of gas fluxes, and can easily be replicated over time and space (Bastviken et al., 2015). The gas flux is determined from the change of the gas concentration in the chamber headspace over time. Floating chambers have been frequently applied for measuring gas fluxes in large rivers, reservoirs and lakes (e.g., Beaulieu et al., 2014; DelSontro et al., 2011; Eugster et al., 2011).

Chamber measurements have been criticized because submerged chamber edges are thought to disrupt the aquatic boundary layer, thereby affecting the gas exchange (Kremer et al., 2003). Comparisons of floating chambers with other flux measurement techniques were performed in lakes, rivers, and estuaries. While some studies have reported a tendency of floating chambers to yield higher fluxes than other methods (Raymond and Cole, 2001; Teodoru et al., 2015), others found reasonable agreement (Gålfalk et al., 2013; Cole et al., 2010).
In streams and rivers, floating chambers have been deployed anchored at one spot (anchored chambers; SandJensen and Staehr, 2012; Crawford et al., 2013), or freely drifting with the water (drifting chambers; Alin et al., 2011; Beaulieu et al., 2012). Although based on the same principle, the two deployment modes have fundamental differences. Because of the higher velocity difference between the chamber and the surface water, anchored chambers in running waters may create additional turbulence around the chamber edges (Kremer et al., 2003). If the effect of this turbulence on fluxes is minor, anchored chambers would be advantageous as the area covered by the chamber can be controlled and because practical work with anchored chambers is relatively simple. Drifting chambers will likely induce less turbulence in the surface water; however it is difficult to control their coverage, potentially resulting in spatially biased measurements. Drifting chambers are also complicated for several reasons, e.g., the presence of obstacles in the streams or in terms of logistics, as the chambers may travel far during measurement periods.

While the establishment of efficient methods for running water gas emissions is needed to improve the global GHG budget, progress in chamber-based methods is prevented by the lack of comparative assessments of anchored versus drifting chambers. In this study, we compared measurements of GHG fluxes and the gas exchange velocity using drifting and anchored chambers in various streams and rivers. Because chamber performance is expected to depend strongly on chamber design, the field experiments were conducted using three different chamber types. In laboratory experiments, we analyzed the flow field and the turbulence under both anchored and drifting chambers at different flow velocities. The primary objective of this study was to answer the following question: do anchored chambers produce reliable measurements of localized GHG fluxes in running waters?

\section{Methods}

\subsection{Chamber measurements in the field}

Field measurements were conducted in nine different rivers and streams in Germany and Poland using three different chambers (Table 1). All three data sets included anchored measurements, where the chambers were tethered to stay at a fixed position as well as drifting measurements, where the chambers freely moved with the current. In two of the data sets $(\mathrm{A}$ and $\mathrm{B})$, the temporal change of $\mathrm{CO}_{2}$ and $\mathrm{CH}_{4}$ concentration in the chamber headspace was measured on a boat using infrared gas analyzers (A: off-axis integrated cavity output spectroscopy (OA-ICOS) gas analyzer, UGGA, Los Gatos Research Inc. USA; B: Fourier transform infrared (FTIR) analyzer, Gasmet 4010, Gasmet, Finland). In the third data set $(\mathrm{C})$, the gas concentration was measured using a built-in and low-cost $\mathrm{CO}_{2}$ sensor (ELG, SenseAir, Swe- 
Table 1. Summary of the three data sets obtained in field measurements. Pictures show the three different chambers used for the anchored and drifting approach. Additional information about the sampling procedures is provided in the Supplement.

\begin{tabular}{|c|c|c|c|}
\hline Data set & A & $\mathrm{B}$ & $\mathrm{C}$ \\
\hline Site & $\begin{array}{c}\text { Five different streams, } \\
\text { north-central } \\
\text { European Plain in } \\
\text { Germany and Poland }\end{array}$ & $\begin{array}{c}\text { Bode river, } \\
\text { Harz Mountains, } \\
\text { central Germany }\end{array}$ & $\begin{array}{l}\text { Three different streams, } \\
\text { Upper Rhine Valley, } \\
\text { southwest Germany }\end{array}$ \\
\hline Chamber volume $\left(\mathrm{m}^{3}\right)$ & 0.0168 & 0.0147 & 0.0068 \\
\hline $\begin{array}{l}\text { Chamber area }\left(\mathrm{m}^{2}\right) \\
\text { (shape) }\end{array}$ & $\begin{array}{c}0.126 \\
\text { (circular) }\end{array}$ & $\begin{array}{c}0.098 \\
\text { (rectangular) }\end{array}$ & $\begin{array}{c}0.066 \\
\text { (circular) }\end{array}$ \\
\hline Chamber height (m) & 0.175 & 0.15 & 0.13 \\
\hline Penetration depth (m) & 0.018 & 0.023 & 0.025 \\
\hline $\begin{array}{l}\text { Chamber gas } \\
\text { measurement }\end{array}$ & $\begin{array}{c}\text { LosGatos, } \mathrm{CO}_{2}, \mathrm{CH}_{4} \\
\text { on boat }\end{array}$ & $\begin{array}{c}\text { FTIR analyzer } \\
\text { (GASMET, Finland) } \\
\text { on boat }\end{array}$ & $\begin{array}{c}\text { Built-in low-cost } \mathrm{CO}_{2} \\
\text { logger (ELG by } \\
\text { SenseAir, Sweden) }\end{array}$ \\
\hline $\begin{array}{l}\text { Dissolved gas } \\
\text { measurement }\end{array}$ & Contros $\mathrm{CO}_{2}$ and $\mathrm{CH}_{4}$ & $\begin{array}{c}\text { Contros } \mathrm{CO}_{2}, \mathrm{CH}_{4} \\
\text { with } \mathrm{GC}\end{array}$ & $\begin{array}{l}\text { UGGA with } \\
\text { membrane contactor }\end{array}$ \\
\hline $\begin{array}{l}\text { Drifting } \\
\text { measurements }\end{array}$ & $\begin{array}{c}\text { Following boat or vice } \\
\text { versa }\end{array}$ & $\begin{array}{l}\text { Freely drifting while } \\
\text { followed with boat }\end{array}$ & Freely drifting \\
\hline $\begin{array}{l}\text { Anchored } \\
\text { measurements }\end{array}$ & $\begin{array}{l}\text { Tethered to a rack in the } \\
\text { middle of the stream }\end{array}$ & $\begin{array}{l}\text { Tethered to } \\
\text { anchored boat }\end{array}$ & $\begin{array}{l}\text { Tethered with rope } \\
\text { from above }\end{array}$ \\
\hline $\begin{array}{l}\text { Number of } \\
\text { measurements }\end{array}$ & $\begin{array}{l}\text { At five sites: two-five pairs of } \\
\text { anchored chamber } \\
\text { measurements } \\
\text { (upstream) and } \\
\text { subsequent floating } \\
\text { chamber runs }\end{array}$ & $\begin{array}{c}\text { For two different } \\
\text { discharge situations: } \\
\text { 10-13 pairs of subsequent } \\
\text { drifting and anchored } \\
\text { chamber measurements } \\
\text { down the river using } \\
\text { a single chamber }\end{array}$ & $\begin{array}{l}\text { At three sites: two-three } \\
\text { subsequent floating } \\
\text { chamber runs and } \\
\text { five parallel anchored } \\
\text { chambers distributed } \\
\text { along the trajectory } \\
\text { of the floating chamber }\end{array}$ \\
\hline
\end{tabular}

den). The chamber used in $\mathrm{C}$ is described in detail elsewhere (Bastviken et al., 2015), the chamber used in A is described in McGinnis et al. (2015).

The chamber flux measurements were supplemented by measurements of dissolved gas concentrations $\left(\mathrm{CO}_{2}\right.$ and in data set $\mathrm{A}$ and $\mathrm{B}$ also $\mathrm{CH}_{4}$ ) in the stream water and in the atmosphere (Table 1). Additional measurements include water temperature and near-surface current velocity, which was measured at selected sites within the study reaches using acoustic or electromagnetic current meters. More details on sampling and instrumentation are provided in Appendix A.

The flux $F\left(\mathrm{mmol} \mathrm{m}^{-2} \mathrm{~d}^{-1}\right)$ of $\mathrm{CO}_{2}$ (all data sets) and $\mathrm{CH}_{4}$ (parts of data set A and B), was calculated from the observed rate of change of the mole fraction $S\left(\mathrm{ppm} \mathrm{s}^{-1}\right)$ of the respective gas in the chamber using (Campeau and Del Giorgio, 2014)

$F=(S \cdot V / A) \cdot t_{1} \cdot t_{2}$,

where $V$ is the chamber gas volume $\left(\mathrm{m}^{3}\right), A$ is the chamber area $\left(\mathrm{m}^{2}\right), t_{1}=8.64 \times 10^{4} \mathrm{~s} \mathrm{~d}^{-1}$ is the conversion factor from seconds to days, and $t_{2}$ is a conversion factor from mole fraction $(\mathrm{ppm})$ to concentration $\left(\mathrm{mmol} \mathrm{m}^{-3}\right)$ at in situ temperature $(T$ in $\mathrm{K}$ ) and atmospheric pressure ( $p$ in $\mathrm{Pa}$ ), according to the ideal gas law:

$t_{2}=p /\left(8.31 \mathrm{~J} \mathrm{~K}^{-1} \mathrm{~mole}^{-1} \cdot T\right) \cdot 1000$.

The gas exchange velocity of the respective gas at in situ temperature $k\left(\mathrm{~m} \mathrm{~d}^{-1}\right)$ was estimated from measured fluxes 
as

$k=F /\left(K_{\mathrm{H}} \cdot\left(p^{\text {water }}-p^{\text {air }}\right)\right)$,

using the partial pressure of $\mathrm{CO}_{2}$ and $\mathrm{CH}_{4}$ in the stream water $\left(p^{\text {water }}\right)$ and in the atmosphere $\left(p^{\text {air }}\right)$. The partial pressures were obtained by multiplication of the measured mole fraction by atmospheric pressure. $K_{\mathrm{H}}$ is the temperaturedependent Henry constant $\left(\mathrm{mmol} \mathrm{m}{ }^{-3} \mathrm{~Pa}^{-1}\right.$; Goldenfum, 2011). The in situ gas exchange velocities were converted to a standardized (independent of temperature and gas diffusivity) exchange velocity $k_{600}$ using the Schmidt number dependence:

$k_{600}=k \cdot(600 / \mathrm{Sc})^{-n}$,

where the temperature-dependent Schmidt numbers (Sc) of both gases were estimated according to Goldenfum (2011). The Schmidt number exponent $n$ describes the dependence of the gas exchange velocity of a particular gas on the diffusion coefficient of this gas in water. We used $n=0.5$, which showed best agreement with measurements for wave-covered and turbulent water surfaces (Jähne and Haußecker, 1998).

\subsection{Turbulence measurements in the lab}

The flow fields under freely drifting and anchored chambers were measured using particle image velocimetry (PIV) in a $3 \mathrm{~m}$ long laboratory flume. The chamber type and geometry was identical to the chamber in data set $\mathrm{C}$ (Table 1). The flow field under the drifting chamber was measured for 50 repeated chamber runs ( $58 \mathrm{~s}$ cumulative velocity observations under the chamber) at a mean flow velocity of $0.10 \mathrm{~m} \mathrm{~s}^{-1}$, the highest flow velocity that could be realized in the flume. Measurements under anchored chambers were performed for $90 \mathrm{~s}$ at a mean flow velocity of $0.10 \mathrm{~m} \mathrm{~s}^{-1}$. Additional measurements were performed at reduced mean flow velocities of 0.08 and $0.06 \mathrm{~m} \mathrm{~s}^{-1}$. As a reference, the undisturbed flow field without chambers was measured for $90 \mathrm{~s}$. Due to the limited length of the laboratory flume it was not possible to measure gas fluxes or estimate the gas exchange velocities.

The flow fields were analyzed by illuminating neutrally buoyant seeding particles (diameter of $20 \mu \mathrm{m}$, polyethylene) within a thin light sheet produced by a double-pulse laser (DualPower 200-15, DantecDynamics) with $5 \mathrm{~ms}$ between pulses. The sampling frequency was $7.5 \mathrm{~Hz}$. Images were recorded in a $145 \times 145 \mathrm{~mm}^{2}$ field of view with a chargecoupled device (CCD) camera (FlowSense 4M MKII, 2048× 2048 pixels, DantecDynamics). The camera was inclined by $30^{\circ}$ to the horizontal, which allowed flow velocities below the chamber to be observed.

The two-dimensional (longitudinal and vertical) flow velocities within the field of view were estimated using an adaptive correlation algorithm (Dynamic Studio, DantecDynamics) with a final spatial resolution of $2.6 \times 2.6 \mathrm{~mm}^{2}$. The longitudinal extent of the observed flow fields $(433 \mathrm{~mm}$ for anchored and $395 \mathrm{~mm}$ for drifting chambers) covered the complete chamber diameter and velocities are reported as a function of distance from the leading chamber edge in both the anchored and the drifting deployment.

The turbulent kinetic energy (TKE) was estimated by assuming isotropy in the unresolved velocity component to be

$\mathrm{TKE}=\frac{3}{4} \overline{u^{\prime 2}+w^{\prime 2}}$,

where $u^{\prime}$ and $w^{\prime}$ denote the temporal fluctuations of the longitudinal and vertical velocity component, respectively, and the overbar denotes temporal averaging.

\subsection{Statistics}

The mean fluxes measured with anchored and drifting chambers in the respective field data sets were compared using paired $t$ tests, comparisons between the data sets were performed using two-sample $t$ tests. Spearman rank correlation coefficients $\left(r_{\mathrm{S}}\right)$ were estimated when testing for correlations between gas exchange velocities from anchored and drifting chambers for each data set. All analyses were performed at a significance level $p<0.05$, unless stated otherwise.

\section{Results}

\subsection{Drifting vs. anchored chamber measurements in the field}

In all measurements, the $\mathrm{CO}_{2}$ and $\mathrm{CH}_{4}$ fluxes were positive, i.e., the streams were sources of both gases to the atmosphere. While the mean $\mathrm{CO}_{2}$ fluxes measured by drifting chambers did not differ significantly among the data sets $\mathrm{B}$ and $\mathrm{C}$, they were about 7-fold higher in data set A (Table 2). In all data sets, anchored chamber fluxes were significantly higher than the corresponding drifting chamber fluxes.

Gas exchange velocities $k_{600}$ estimated from $\mathrm{CO}_{2}$ measurements in the drifting chamber deployments $\left(k_{600} \mathrm{CO}_{2 \_} \mathrm{d}\right)$ ranged between 0.2 and $8.1 \mathrm{md}^{-1}$. They varied widely within each data set (Table 2), but in contrast to the current velocities mean values of $k_{600} \mathrm{CO}_{2} \mathrm{~d}_{\mathrm{d}} \mathrm{did}$ not significantly differ among the data sets. In all data sets, however, $k_{600}$ from anchored chambers $\left(k_{600 \_} \mathrm{CO}_{2 \_}\right)$differed significantly from that of drifting chambers (Fig. 1a). Except for data set A, both were weakly correlated to each other $\left(r_{\mathrm{S}}=0.49\right.$, $p=0.01, r_{\mathrm{S}}=0.76$, and $p<0.001$ for data set $\mathrm{B}$ and $\mathrm{C}$, respectively) (Fig. 1b). With only a few exceptions, the gas exchange velocities under anchored chambers were higher than those under drifting chambers with individual measurements, $k_{600 \_} \mathrm{CO}_{2 \_}$a being up to 20 times higher than $k_{600 \_} \mathrm{CO}_{2 \_} \mathrm{d}$. The average ratio of both velocities was $2.2,6.2$, and 4.0 for data set $\mathrm{A}, \mathrm{B}$, and $\mathrm{C}$, respectively (Table 2 ).

When both gases were measured, the gas exchange velocities estimated from $\mathrm{CO}_{2}$ fluxes were strongly correlated to 

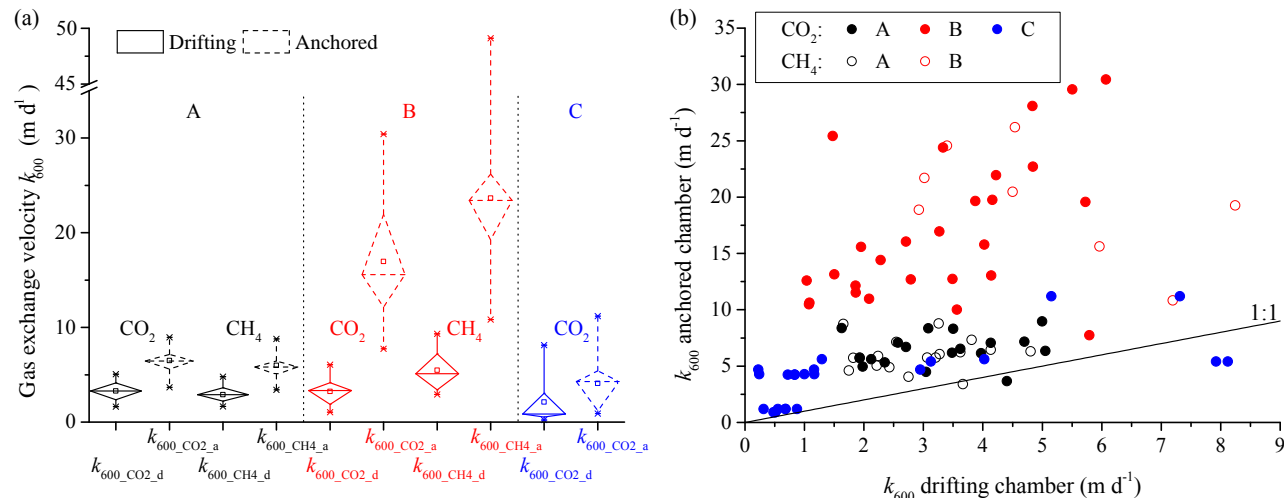

Figure 1. (a) Box plots of the standardized gas exchange $\left(k_{600}\right)$ velocity measured using drifting (solid lines) and anchored (dashed lines) flux chambers in data set A (black), B (red), and C (blue). The diamond-shaped boxes encompass the 25-75 percentile range, whiskers show minimum and maximum, and open squares and horizontal lines mark mean and median values, respectively. (b) $k_{600}$ estimated from anchored chamber deployments versus that from drifting chambers for the data sets A-C (see color code in the inset.). Filled symbols show $k_{600}$ estimated from $\mathrm{CO}_{2}$ fluxes; open symbols are based on $\mathrm{CH}_{4}$ fluxes. The solid line shows a $1: 1$ relationship.

Table 2. Discharge rate, flow velocities, gas fluxes $\left(F_{\mathrm{CO}_{2}}, F_{\mathrm{CH}_{4}}\right)$, and gas exchange velocities $\left(k_{600} \mathrm{CO}_{2}, k_{600} \mathrm{CH}_{4}\right)$ estimated from drifting chambers (subscript $d$ ) and from anchored (subscript a) chambers during the three field campaigns (A-C, cf. Table 1). Except for discharge, all values are given as mean \pm standard deviation.

\begin{tabular}{|c|c|c|c|}
\hline Data set & A & B & $\mathrm{C}$ \\
\hline No. of samples $n$ & $\begin{array}{l}n_{\mathrm{CO}_{2}}=18 \\
n_{\mathrm{CH}_{4}}=18\end{array}$ & $\begin{array}{r}n_{\mathrm{CO}_{2}}=27 \\
n_{\mathrm{CH}_{4}}=9\end{array}$ & $\begin{array}{r}n_{\mathrm{CO}_{2}}=24 \\
n_{\mathrm{CH}_{4}}=0\end{array}$ \\
\hline Discharge $\left(\mathrm{m}^{3} \mathrm{~s}^{-1}\right)$ & $0.6-1.4$ & $7.7-12.8$ & $0.1-7.6$ \\
\hline Flow velocity $\left(\mathrm{ms}^{-1}\right)$ & $0.21 \pm 0.07$ & $0.60 \pm 0.12$ & $0.30 \pm 0.07$ \\
\hline$F_{\mathrm{CO}_{2 \_\mathrm{a}}}\left(\mathrm{mmolm}^{-2}\right.$ day $\left.^{-1}\right)$ & $742 \pm 282$ & $302 \pm 148$ & $103 \pm 47$ \\
\hline$F_{\mathrm{CO}_{2 \_} \mathrm{d}}\left(\mathrm{mmolm}^{-2} \mathrm{day}^{-1}\right)$ & $363 \pm 139$ & $55 \pm 30$ & $49 \pm 36$ \\
\hline$k_{600 \_\mathrm{CO}_{2 \_\mathrm{a}}}\left(\mathrm{m} \mathrm{day}^{-1}\right)$ & $6.5 \pm 1.4$ & $17 \pm 6.4$ & $4.1 \pm 2.8$ \\
\hline$k_{600 \_\mathrm{CO}_{2 \_} \mathrm{d}}\left(\mathrm{m} \mathrm{day}^{-1}\right)$ & $3.3 \pm 1.1$ & $3.2 \pm 1.5$ & $2.1 \pm 2.5$ \\
\hline$k_{600 \_\mathrm{CO}_{2 \_} \mathrm{a}} / k_{600} \mathrm{CO}_{2 \_\mathrm{d}}$ & $2.2 \pm 0.9$ & $6.2 \pm 3.2$ & $4.0 \pm 5.0$ \\
\hline$F_{\mathrm{CH}_{4 \_} \mathrm{a}}\left(\mathrm{mmol} \mathrm{m}^{-2}\right.$ day $\left.^{-1}\right)$ & $4.31 \pm 1.35$ & $1.55 \pm 0.71$ & - \\
\hline$F_{\mathrm{CH}_{4 \_} \mathrm{d}}\left(\mathrm{mmol} \mathrm{m}^{-2}\right.$ day $\left.^{-1}\right)$ & $2.12 \pm 0.86$ & $0.37 \pm 0.16$ & - \\
\hline$k_{600 \_\mathrm{CH}_{4 \_\mathrm{a}}}\left(\mathrm{m} \mathrm{day}^{-1}\right)$ & $6.0 \pm 1.4$ & $23.0 \pm 10.8$ & - \\
\hline$k_{600 \_} \mathrm{CH}_{4 \_} \mathrm{d}\left(\mathrm{m} \mathrm{day}^{-1}\right)$ & $2.9 \pm 0.9$ & $5.5 \pm 2.4$ & - \\
\hline$k_{600 \_} \mathrm{CH}_{4-} \mathrm{a} / k_{600} \mathrm{CH}_{4-\mathrm{d}}$ & $2.3 \pm 1.0$ & $4.8 \pm 2.1$ & - \\
\hline
\end{tabular}

those estimated from $\mathrm{CH}_{4}$ measurements for both deployment types. Small but significant differences were observed between $k_{600} \mathrm{CO}_{2} \mathrm{~d}$ and $k_{600} \mathrm{CH}_{4} \mathrm{~d}$, whereas the $\mathrm{CO}_{2}$-based estimates were on average slightly higher in data set $\mathrm{A}$ and lower in data set $\mathrm{B}$ (Fig. 1a). In accordance with the $\mathrm{CO}_{2}$ based estimates, $k_{600}$ estimated from $\mathrm{CH}_{4}$ was higher under anchored than under drifting chambers (Table 2), and the ratio $k_{600 \_a} / k_{600 \_d}$ did not differ significantly between both gases.

When combining all data sets, there was no correlation between gas exchange velocities and the measured current velocity for drifting chambers for either $\mathrm{CO}_{2}$ or $\mathrm{CH}_{4}$ (Fig. 2a). However, for anchored chamber deployments, $k_{600}$ a was positively correlated to current speed in data set $\mathrm{A}\left(r_{\mathrm{S}}=\right.$ $0.54, p=0.02)$ and $\mathrm{B}\left(r_{\mathrm{S}}=0.7, p<0.001\right)$. The ratio of the gas exchange velocities estimated from both deployment types was positively correlated to current speed when all three data sets were combined $\left(r_{\mathrm{S}}=0.66, p<0.001\right)$, but no significant correlations were observed within the individual data sets (Fig. 2b).

\subsection{Flow field and turbulence under chambers}

The laboratory measurements revealed pronounced differences in the flow fields and turbulence under the anchored and drifting chambers. The mean longitudinal flow velocity was strongly reduced within the submerged part of the anchored chamber and increased below the submerged chamber edge. Recirculating eddies were formed under the leading (upstream) edge of the chamber (vector graphs of the mean velocity distributions are provided in Appendix B). These eddies detached and injected turbulence below the chamber (Fig. 3). The turbulent kinetic energy which was produced by the submerged edge of the anchored chambers increased with increasing current speed (Appendix B). Under the drifting chambers, the flow velocities were slightly enhanced below the submerged chamber edge, but no recirculating eddies were formed.

The penetration depth of the chamber edges varied with time as the chamber moved vertically on the rough water surface (see Appendix B for snapshots of instantaneous velocity distributions and chamber penetration). However, at the same flow velocity the average penetration depth of the anchored chamber was higher than that of the drifting chamber (Fig. 3). 

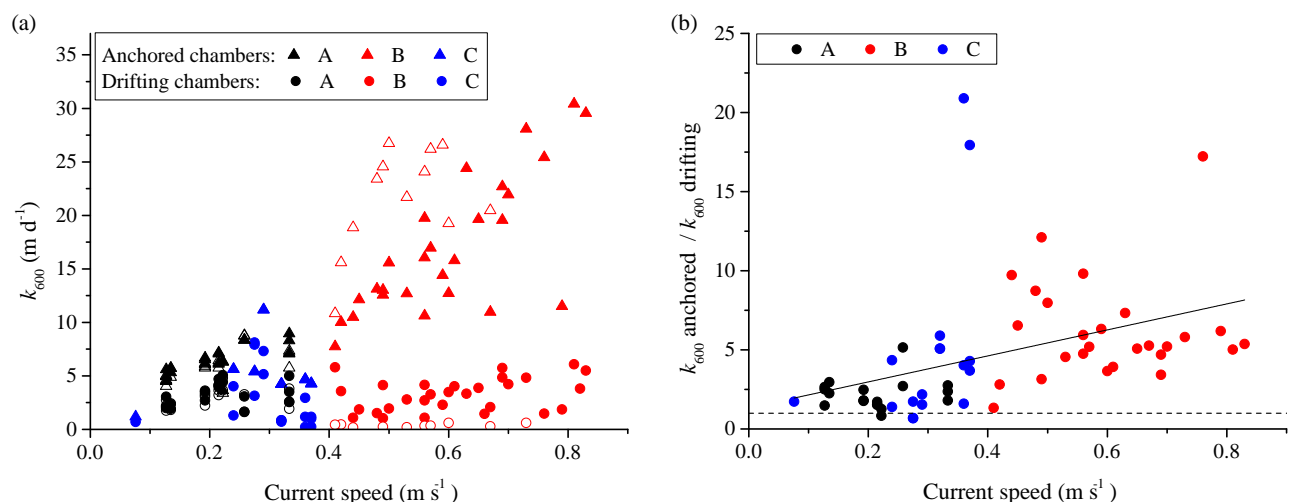

Figure 2. (a) Gas exchange velocity $k_{600}$ from anchored (triangles) and drifting (circles) chambers versus current velocity for the three field data sets (A-C, colors). Filled symbols show data obtained from $\mathrm{CO}_{2}$, open symbols are based on $\mathrm{CH}_{4}$ fluxes. (b) Ratio of the gas exchange velocities from anchored and drifting chambers versus current speed (filled symbols: $\mathrm{CO}_{2}$; open symbols: $\mathrm{CH}_{4}$; colors correspond to the different data sets). The dashed line indicates a constant ratio of 1 and the solid line shows a linear regression of the combined data sets $\left(r_{\mathrm{S}}=0.66, p<0.001\right)$.

\section{Discussion}

\subsection{Chamber bias in anchored deployments}

Our field observations showed consistently higher gas exchange velocities and gas fluxes measured with anchored in comparison to freely drifting chambers in a variety of small streams with flow velocities between 0.08 and $0.8 \mathrm{~m} \mathrm{~s}^{-1}$. Detailed observations of the flow field and turbulence under both types of chambers in the laboratory revealed a reduction of mean flow velocity and the generation of chamberinduced turbulence due to the shedding of eddies at the upstream part of the submerged edge of the anchored chamber. Under identical hydraulic conditions, anchored chambers penetrated deeper into the water, which we attribute to a partial diversion of the strong horizontal drag force imposed by the flow into the vertical direction. In combination, horizontal current shear and deeper penetration caused an increase in magnitude of chamber-induced turbulence with increasing difference in velocity between the water flow and the chamber (Fig. B1). This mechanism has been suggested in previous studies of floating chamber performance in water bodies, although there are mixed results regarding its importance (Cole et al., 2010; Gålfalk et al., 2013; Vachon et al., 2010).

The laboratory observation agrees with our field measurements, where the ratio of the fluxes measured with anchored and with drifting chambers was comparably small at flow velocities $<0.2 \mathrm{~m} \mathrm{~s}^{-1}$. However, even at low flow velocities, the gas exchange velocity was enhanced by more than a factor of 2 in the anchored deployment. At higher flow velocities $\left(>0.2 \mathrm{~m} \mathrm{~s}^{-1}\right)$ typical for rivers and streams, chamberinduced turbulence obviously dominated the gas flux into the anchored chambers.
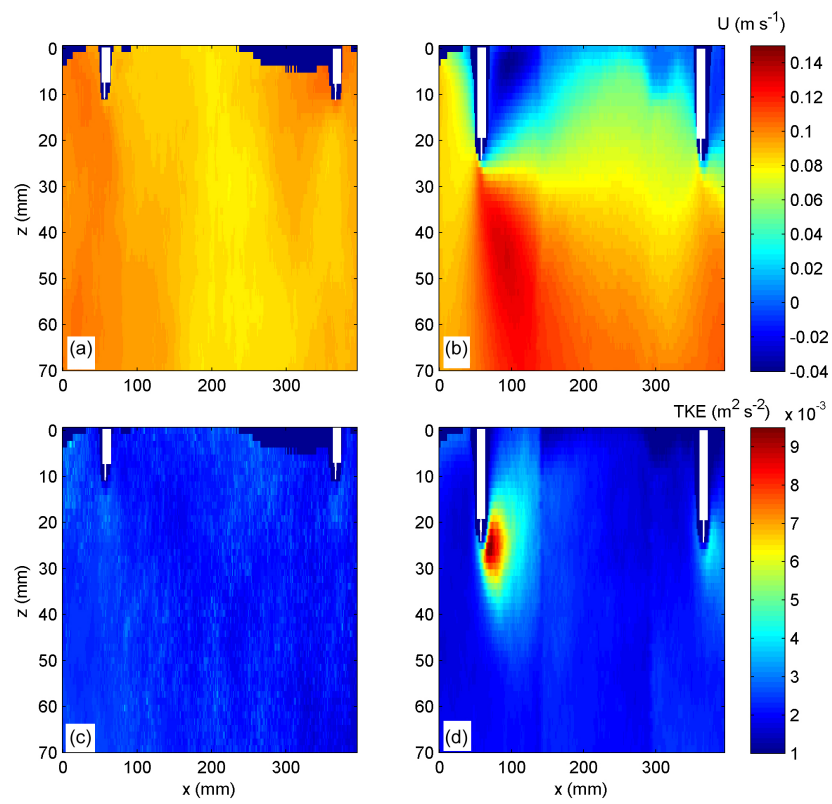

Figure 3. Laboratory measurements of the mean longitudinal flow velocities $(U)$ (a) below a drifting chamber and (b) below an anchored chamber. Mean turbulent kinetic energy (TKE) of the flow fields below (c) the drifting chamber and (d) the anchored chamber. $z$ and $x$ refer to depth and longitudinal distance respectively. Chamber edges are blocked out (white) and regions without sufficient observations for temporal averaging are marked by a dark blue color. The flow direction is from left to right and the mean flow velocity was $0.1 \mathrm{~m} \mathrm{~s}^{-1}$.

The large (several-fold) potential overestimation of fluxes measured with anchored chambers calls into question its suitability for application in running waters, particularly at high flow rates. This agrees with the observations of Teodoru et al. (2015) who reported a linear dependency of the gas ex- 

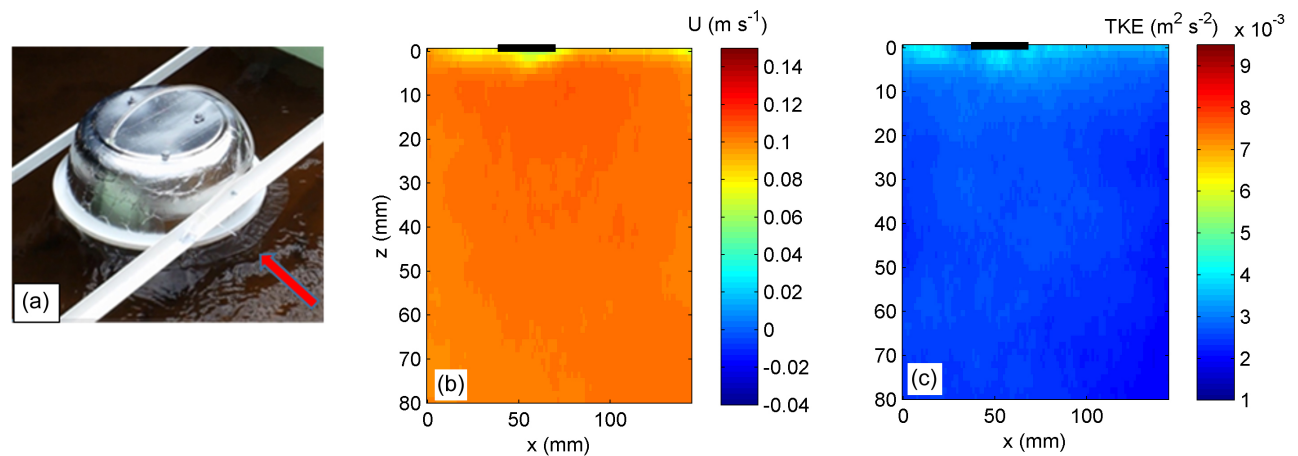

Figure 4. (a) Flying chamber design without penetration of the water surface by the chamber edges but using a plastic foil collar (marked by the red arrow) for sealing. The chamber is fixed above the water surface by a supporting frame. (b) Distribution of mean longitudinal flow velocities $(U)$ and (c) turbulent kinetic energy (TKE) of the flow field below the front edge of a piece of static foil (marked by the black bar) at the water surface. The direction of flow was from left to right; $x$ and $y$ refer to longitudinal distance and depth, respectively. The mean flow velocity was $0.10 \mathrm{~m} \mathrm{~s}^{-1}$. Color scales are identical to that of Fig. 3.

change velocity under anchored chambers on the water velocity relative to the chamber in a large river.

\subsection{Correction methods and chamber optimization}

The correlation of the anchored chamber gas exchange velocity with flow velocity observed in our study could provide a potential means for correcting the artificial chamber flux, if the corresponding drifting chamber gas exchange velocity were also a function of flow velocity. However, no such correlation was present in our field observations, indicating that near-surface flow velocity is a poor predictor for the gas exchange velocities in streams. Therefore, it can be expected that river depth and bed roughness affect the near-surface turbulence more than flow velocity (Moog and Jirka, 1999; Raymond et al., 2012).

As the correction of the effects of chamber-induced turbulence on measured fluxes seems unlikely, it would be more reasonable to optimize the chamber design to completely avoid or to at least reduce this effect. The rectangular chamber B produced the largest error, although it remained unclear from our measurements whether this was caused by the geometry of the chamber or by the high flow velocity in data set B. On this basis, we recommend the use of more streamlined circular chambers to minimize the error under drifting conditions. Crawford et al. (2013) and McMahon and Dennehy (1999) used streamlined (canoe-shaped) instead of cylindrical or rectangular chambers to minimize the generation of chamber-induced turbulence at the upstream chamber edge during anchored chamber deployments. However, they did not provide evidence that this goal was reached.

Another approach to minimize the bias of anchored chambers would be to design chambers without submerged rigid walls. Submergence of the chamber edges can be avoided completely by using a piece of thin plastic foil which adheres to the water surface to seal the chamber headspace (Fig. 4a). Laboratory (PIV) measurements of the flow field were performed under a piece of foil, mimicking a chamber deployed in anchored mode. The measurements revealed a strong reduction of flow disturbances and chamber-induced turbulence (Fig. 4) in comparison to both anchored and drifting chambers. Such "flying" chambers require a frame to keep the chamber above the water surface, which can be supported by floats at a larger lateral distance to the chamber or, in small streams, also by a fixation at the river bank.

\subsection{Implications for chamber-based flux measurements}

Our study clearly shows that anchored chambers strongly overestimate the gas flux in running water and are not suited to quantify greenhouse gas fluxes in streams and rivers. One possible way forward to reduce this bias while still maintaining the practical advantages of the anchored chambers could be the use of "flying" (anchored) chambers with flexible foil sealing at the water surface. Drifting chambers provide a practical and reliable solution, although they are not free of potential spatial bias. Because their measurement locations are difficult to control, their trajectories may not be representative of the areal mean flux from the study reach. Regions with locally enhanced turbulence, e.g., stream reaches with large emerging roughness of the river bed, cannot be surveyed with drifting chambers; however the gas exchange velocity is highest at these sites (Moog and Jirka, 1999). Similarly, mean flow trajectories may bypass backwaters and regions of reduced flow velocity along the stream banks. Observations in reservoirs and river impoundments revealed that the enhanced sedimentation of particulate organic matter can make these zones emission hot spots (Maeck et al., 2013; DelSontro et al., 2011). Anchored chamber deployments may provide a useful extension of drifting chamber measurements at such sites, if the flow velocity is sufficiently small. To truly validate a reliable chamber method for small streams, a multi-method comparison study, including tracer additions, should be performed. 
This study shows that flux chamber approaches to measure GHG fluxes from running waters have a high potential, given sufficient knowledge about appropriate chamber design and deployment approaches. Thus, flux chambers are emerging as an important method to constrain greenhouse gas fluxes from stream networks. 


\section{Appendix A: Additional information on the field data sets}

\section{A1 Data set A}

Field measurements of five streams in the north-central European Plain in Germany and Poland were conducted during October 2014. Gaseous $\mathrm{CO}_{2}$ and $\mathrm{CH}_{4}$ emissions were measured at the water-air interface with a drifting chamber attached to an Ultraportable Greenhouse Gas Analyzer (UGGA; Los Gatos Research, Inc., USA). The chamber was connected to the UGGA placed in a boat via two gas-tight tubes (Tygon 2375), creating a circulation of air being sucked in and pumped out. For the anchored measurements, we tethered the chamber to a rack in the middle of the respective stream, in which we placed the sensors for continuously dissolved $\mathrm{CO}_{2}$ and $\mathrm{CH}_{4}$ measurements $\left(\mathrm{HydroC}{ }^{\mathrm{TM}}\right.$; CONTROS Systems \& Solutions GmbH, Germany). Subsequently, we floated the same chamber down a predefined stream section following the boat freely at the speed of the current. During the chamber measurements, the UGGA continuously measured the gaseous $\mathrm{CO}_{2}$ and $\mathrm{CH}_{4}$ accumulation in the chamber (frequency $1 \mathrm{~s}$ ). Flow velocity was measured with an Acoustic Digital Current meter (OTT, Germany).

\section{A2 Data set B}

Measurements were performed on the Bode River between Egeln-Nord and Staßfurt on 7 April 2014 (summer base flow $7.7 \mathrm{~m}^{3} \mathrm{~s}^{-1}$ ) and 12 March 2015 (winter high flow $12.8 \mathrm{~m}^{3} \mathrm{~s}^{-1}$ ).

The flux of $\mathrm{CO}_{2}$ and $\mathrm{CH}_{4}$ between water and the atmosphere was measured by a rectangular floating chamber, which was connected to an FTIR analyzer (GASMET 4010, Finland). Measurements were performed from a boat while it was drifting down the river. For a single measurement, the chamber was placed at the water surface for up to $5 \mathrm{~min}$ and $\mathrm{CO}_{2}$ and $\mathrm{CH}_{4}$ change inside the chamber was measured every $30 \mathrm{~s}$. To compare drifting and fixed chamber measurements, the boat was then stopped by an anchor and measurements continued for another 3-5 min. During this stationary measurement, current velocity was measured with an electromagnetic current meter (MF-Pro, Ott, Germany) and water temperature were measured by handheld probes (ProfiLine Multi,WTW, Germany).
The concentration of $\mathrm{CO}_{2}$ in the water was continuously measured by a submersible probe $\left(\mathrm{HydroC}^{\mathrm{TM}}\right.$; CONTROS Systems \& Solutions GmbH, Germany). Additionally, samples for $\mathrm{CH}_{4}$ analysis were taken in plastic syringes and later analyzed by headspace gas chromatography.

Water temperature was continuously measured by temperature loggers (Tidbit, Onset, USA). The barometric pressure was recorded by the FTIR analyzer.

Under drifting conditions the $\mathrm{CH}_{4}$ flux was often below the detection limit; while there was always a positive $\mathrm{CH}_{4}$ flux in anchored chamber deployments.

\section{A3 Data set C}

Chambers with a cross-sectional area of $0.066 \mathrm{~m}^{2}$ and volume of $6.8 \mathrm{~L}$ were covered by aluminum foil to reduce the internal heating and equipped with a Styrofoam material to keep the chamber body floating on water surface. The chambers were equipped with an internal $\mathrm{CO}_{2}$ logger system that is positioned inside the headspace of the chamber (Bastviken et al., 2015). The non-dispersive infrared (NDIR) $\mathrm{CO}_{2}$ logger (ELG, SenseAir, Sweden; www.senseair.se) measures $\mathrm{CO}_{2}$ in the range of $0-5000 \mathrm{ppm}$. The logger measures simultaneously $\mathrm{CO}_{2}$, temperature, and relative humidity, and operates at temperature and humidity of $0-50{ }^{\circ} \mathrm{C}$ and $0-99 \%$ (noncondensing conditions) respectively. The loggers were calibrated by the manufacturer and operated with $9 \mathrm{~V}$ batteries. The measurement interval was adjusted to be $30 \mathrm{~s}$; more information of technical specifications are provided elsewhere (Bastviken et al., 2015).

Chambers were deployed fixed at a certain position (anchored) and freely drifting. Triplicate measurements were conducted during each drifting run, and three runs were conducted at each site. The anchored chambers were then used for measuring the flux of $\mathrm{CO}_{2}$ at different locations along the pathways of the drifting chambers. The chamber flux measurements were supplemented by measurements of dissolved gas $\mathrm{CO}_{2}$ and $\mathrm{CH}_{4}$ concentrations in the stream waters at each anchored stations for each run. Continuous measurements of $\mathrm{CO}_{2}$ and methane in the middle of the stream were conducted using a membrane equilibrator (Liqui-Cel MiniModule, Membrana, USA) connected with an Ultraportable Greenhouse Gas Analyzer (UGGA; Los Gatos Research, Inc., USA). The water samples were pumped through the membrane contactor using a peristaltic pump at a constant flow rate. 
Appendix B: Mean flow and turbulence under anchored chambers at different current speeds
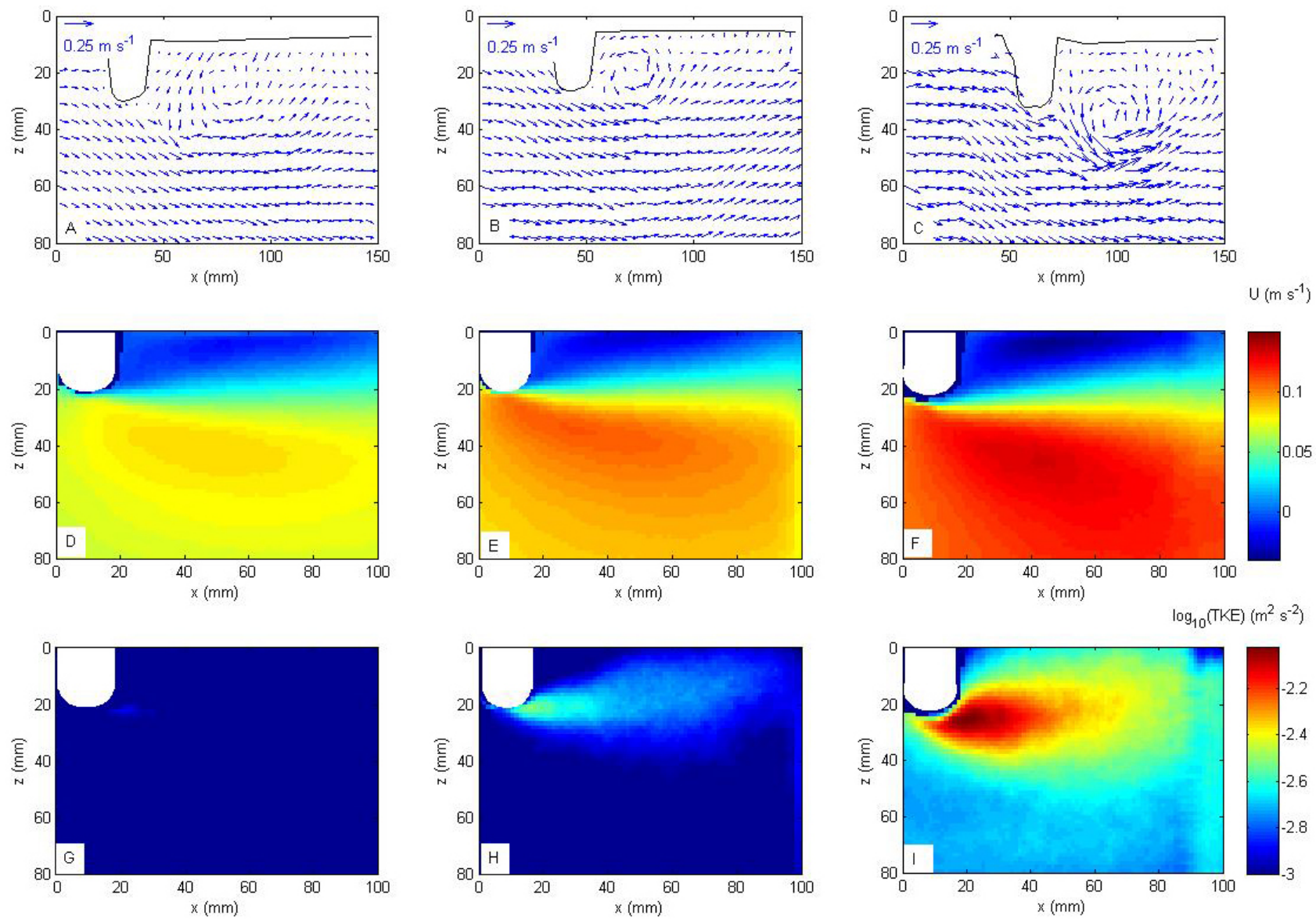

Figure B1. Laboratory measurements of flow velocity and turbulence under anchored chambers at different mean current speeds (left: $0.06 \mathrm{~m} \mathrm{~s}^{-1}$, middle: $0.08 \mathrm{~m} \mathrm{~s}^{-1}$, right: $0.10 \mathrm{~m} \mathrm{~s}^{-1}$. Panels (a-c) show examples of instantaneous velocities around the leading edge of the chambers. The water surface and the leading chamber edge are marked by solid black lines. (d-f) Temporal mean longitudinal flow velocity $(U)$. (g-i) Mean turbulent kinetic energy (TKE). The chamber edges are masked out (white) and regions without sufficient observations ( $<90 \mathrm{~s}$ for the anchored cases) are displayed in dark blue. The direction of flow was from left to right; $x$ and $z$ refer to longitudinal distance and depth, respectively. 
Acknowledgements. Parts of this study were financially supported by the German Research Foundation (grant no. LO 1150/9-1) and conducted within the LandScales project ("Connecting processes and structures driving the landscape carbon dynamics over scales") financed by the Leibniz Association within the Joint Initiative for Research and Innovation (BMBF) and (partially) carried out within the SMART Joint Doctorate (Science for the MAnagement of Rivers and their Tidal systems) funded with the support of the Erasmus Mundus program of the European Union and the Swiss National Science Foundation (grant no. PA00P2_142041). The development and production of the chambers with built-in $\mathrm{CO}_{2}$ loggers (data set $\mathrm{C}$ ) was supported by the Swedish Research Council VR. Funding for an initial workshop was carried out by the IGB cross-cutting research domain "Aquatic Boundaries and Linkages". We gratefully acknowledge the financial support of German Academic Exchange Service (DAAD) (Sustainable water management Program (NAWAM), grant no. A/12/91768). We thank Simone Langhans for her fruitful input, which shaped the core idea of the presented study. Finally, we thank the two anonymous reviewers for constructive input that improved the manuscript.

Edited by: H. Niemann

\section{References}

Alin, S. R., Rasera, M., Salimon, C. I., Richey, J. E., Holtgrieve, G. W., Krusche, A. V., and Snidvongs, A.: Physical controls on carbon dioxide transfer velocity and flux in low-gradient river systems and implications for regional carbon budgets, J. Geophys. Res.-Biogeo., 116, G01009, doi:10.1029/2010jg001398, 2011.

Aufdenkampe, A. K., Mayorga, E., Raymond, P. A., Melack, J. M., Doney, S. C., Alin, S. R., Aalto, R. E., and Yoo, K.: Riverine coupling of biogeochemical cycles between land, oceans, and atmosphere, Front. Ecol. Environ., 9, 53-60, doi:10.1890/100014, 2011.

Baldocchi, D.: Measuring fluxes of trace gases and energy between ecosystems and the atmosphere - the state and future of the eddy covariance method, Glob. Change Biol., 20, 3600-3609, doi:10.1111/gcb.12649, 2014.

Bastviken, D., Tranvik, L. J., Downing, J. A., Crill, P. M., and Enrich-Prast, A.: Freshwater methane emissions offset the continental carbon sink, Science, 331, 50-50, doi:10.1126/science.1196808, 2011.

Bastviken, D., Sundgren, I., Natchimuthu, S., Reyier, H., and Gålfalk, M.: Technical Note: Cost-efficient approaches to measure carbon dioxide $\left(\mathrm{CO}_{2}\right)$ fluxes and concentrations in terrestrial and aquatic environments using mini loggers, Biogeosciences, 12, 3849-3859, doi:10.5194/bg-12-3849-2015, 2015.

Battin, T. J., Kaplan, L. A., Findlay, S., Hopkinson, C. S., Marti, E., Packman, A. I., Newbold, J. D., and Sabater, F.: Biophysical controls on organic carbon fluxes in fluvial networks, Nat. Geosci., 1, 95-100, doi:10.1038/ngeo101, 2008.

Beaulieu, J. J., Shuster, W. D., and Rebholz, J. A.: Controls on gas transfer velocities in a large river, J. Geophys. Res.-Biogeo., 117, G02007, doi:10.1029/2011jg001794, 2012.

Beaulieu, J. J., Smolenski, R. L., Nietch, C. T., Townsend-Small, A., and Elovitz, M. S.: High methane emissions from a midlatitude reservoir draining an agricultural watershed, Environ. Sci. Technol., 48, 11100-11108, doi:10.1021/es501871g, 2014.

Butman, D. and Raymond, P. A.: Significant efflux of carbon dioxide from streams and rivers in the United States, Nat. Geosci., 4, 839-842, 2011.

Campeau, A. and Del Giorgio, P. A.: Patterns in $\mathrm{CO}_{2}$ and $\mathrm{CO}_{2}$ concentrations across boreal rivers: Major drivers and implications for fluvial greenhouse emissions under climate change scenarios, Glob. Change Biol., 20, 1075-1088, 2014.

Cole, J. J., Prairie, Y. T., Caraco, N. F., McDowell, W. H., Tranvik, L. J., Striegl, R. G., Duarte, C. M., Kortelainen, P., Downing, J. A., Middelburg, J. J., and Melack, J.: Plumbing the global carbon cycle: integrating inland waters into the terrestrial carbon budget, Ecosystems, 10, 171-184, doi:10.1007/s10021-0069013-8, 2007.

Cole, J. J., Bade, D. L., Bastviken, D., Pace, M. L., and Van de Bogert, M.: Multiple approaches to estimating air-water gas exchange in small lakes, Limnol. Oceanogr. Meth., 8, 285-293, doi:10.4319/lom.2010.8.285, 2010.

Crawford, J. T., Striegl, R. G., Wickland, K. P., Dornblaser, M. M., and Stanley, E. H.: Emissions of carbon dioxide and methane from a headwater stream network of interior Alaska, J. Geophys. Res.-Biogeo., 118, 482-494, doi:10.1002/jgrg.20034, 2013.

DelSontro, T., Kunz, M. J., Kempter, T., Wüest, A., Wehrli, B., and Senn, D. B.: Spatial heterogeneity of methane ebullition in a large tropical reservoir, Environ. Sci. Technol., 45, 9866-9873, doi:10.1021/es2005545, 2011.

Eugster, W., DelSontro, T., and Sobek, S.: Eddy covariance flux measurements confirm extreme $\mathrm{CO}_{2}$ emissions from a Swiss hydropower reservoir and resolve their short-term variability, Biogeosciences, 8, 2815-2831, doi:10.5194/bg-8-2815-2011, 2011.

Gålfalk, M., Bastviken, D., Fredriksson, S., and Arneborg, L.: Determination of the piston velocity for water-air interfaces using flux chambers, acoustic Doppler velocimetry, and IR imaging of the water surface, J. Geophys. Res.-Biogeo., 118, 770-782, doi:10.1002/jgrg.20064, 2013.

Goldenfum, J. A.: GHG Measurement Guidelines for Freshwater Reservoirs, UNESCO/IHA, London, UK, 139 pp., 2011.

Halbedel, S. and Koschorreck, M.: Regulation of $\mathrm{CO}_{2}$ emissions from temperate streams and reservoirs, Biogeosciences, 10, 7539-7551, doi:10.5194/bg-10-7539-2013, 2013.

Hotchkiss, E. R., Hall Jr., R. O., Sponseller, R. A., Butman, D., Klaminder, J., Laudon, H., Rosvall, M., and Karlsson, J.: Sources of and processes controlling $\mathrm{CO}_{2}$ emissions change with the size of streams and rivers, Nature Geosci., 8, 696-699, doi:10.1038/ngeo2507, 2015.

Jähne, B. and Haußecker, H.: Air-water gas exchange, Annu. Rev. Fluid Mech., 30, 443-468, 1998.

Koprivnjak, J. F., Dillon, P. J., and Molot, L. A.: Importance of $\mathrm{CO}_{2}$ evasion from small boreal streams, Global Biogeochem. Cy., 24, Gb4003, doi:10.1029/2009gb003723, 2010.

Kremer, J. N., Nixon, S. W., Buckley, B., and Roques, P.: Technical note: Conditions for using the floating chamber method to estimate air-water gas exchange, Estuaries, 26, 985-990, doi:10.1007/BF02803357, 2003.

Le Quéré, C., Peters, G. P., Andres, R. J., Andrew, R. M., Boden, T. A., Ciais, P., Friedlingstein, P., Houghton, R. A., Marland, G., Moriarty, R., Sitch, S., Tans, P., Arneth, A., Arvanitis, A., Bakker, D. C. E., Bopp, L., Canadell, J. G., Chini, L. P., 
Doney, S. C., Harper, A., Harris, I., House, J. I., Jain, A. K., Jones, S. D., Kato, E., Keeling, R. F., Klein Goldewijk, K., Körtzinger, A., Koven, C., Lefèvre, N., Maignan, F., Omar, A., Ono, T., Park, G.-H., Pfeil, B., Poulter, B., Raupach, M. R., Regnier, P., Rödenbeck, C., Saito, S., Schwinger, J., Segschneider, J., Stocker, B. D., Takahashi, T., Tilbrook, B., van Heuven, S., Viovy, N., Wanninkhof, R., Wiltshire, A., and Zaehle, S.: Global carbon budget 2013, Earth Syst. Sci. Data, 6, 235-263, doi:10.5194/essd-6-235-2014, 2014.

Maeck, A., DelSontro, T., McGinnis, D. F., Fischer, H., Flury, S., Schmidt, M., Fietzek, P., and Lorke, A.: Sediment trapping by dams creates methane emission hotspots, Environ. Sci. Technol., 47, 8130-8137, 2013.

Marion, A., Nikora, V., Puijalon, S., Bouma, T., Koll, K., Ballio, F., Tait, S., Zaramella, M., Sukhodolov, A., O'Hare, M., Wharton, G., Aberle, J., Tregnaghi, M., Davies, P., Nepf, H., Parker, G., and Statzner, B.: Aquatic interfaces: a hydrodynamic and ecological perspective, J. Hydraul. Res., 52, 1-15, doi:10.1080/00221686.2014.968887, 2014.

McGinnis, D. F., Kirillin, G., Tang, K. W., Flury, S., Bodmer, P., Engelhardt, C., Casper, P., and Grossart, H.-P.: Enhancing Surface Methane Fluxes from an Oligotrophic Lake: Exploring the Microbubble Hypothesis, Environ. Sci. Technol., 49, 873-880, doi:10.1021/es503385d, 2015.

McMahon, P. B. and Dennehy, K. F.: $\mathrm{N}_{2} \mathrm{O}$ emissions from a nitrogen-enriched river, Environ. Sci. Technol., 33, 21-25, doi:10.1021/es980645n, 1999.

Moog, D. and Jirka, G.: Stream reaeration in nonuniform flow: macroroughness enhancement, J. Hydraul. Eng.-ASCE, 125, 1116, doi:10.1061/(ASCE)0733-9429(1999)125:1(11), 1999.

Raymond, P. A. and Cole, J. J.: Gas exchange in rivers and estuaries: choosing a gas transfer velocity, Estuaries, 24, 312-317, doi:10.2307/1352954, 2001.

Raymond, P. A., Zappa, C. J., Butman, D., Bott, T. L., Potter, J., Mulholland, P., Laursen, A. E., McDowell, W. H., and Newbold, D.: Scaling the gas transfer velocity and hydraulic geometry in streams and small rivers, Limnol. Oceanogr. Fluids Environ., 2, 41-53, doi:10.1215/21573689-1597669, 2012.
Raymond, P. A., Hartmann, J., Lauerwald, R., Sobek, S., McDonald, C., Hoover, M., Butman, D., Striegl, R., Mayorga, E., Humborg, C., Kortelainen, P., Durr, H., Meybeck, M., Ciais, P., and Guth, P.: Global carbon dioxide emissions from inland waters, Nature, 503, 355-359, doi:10.1038/nature12760, 2013.

Sand-Jensen, K. and Staehr, P.: $\mathrm{CO}_{2}$ dynamics along Danish lowland streams: water-air gradients, piston velocities and evasion rates, Biogeochemistry, 111, 615-628, doi:10.1007/s10533-0119696-6, 2012.

Teodoru, C. R., Nyoni, F. C., Borges, A. V., Darchambeau, F., Nyambe, I., and Bouillon, S.: Dynamics of greenhouse gases $\left(\mathrm{CO}_{2}, \mathrm{CO}_{2}, \mathrm{~N}_{2} \mathrm{O}\right)$ along the Zambezi River and major tributaries, and their importance in the riverine carbon budget, Biogeosciences, 12, 2431-2453, doi:10.5194/bg-12-2431-2015, 2015.

Tranvik, L. J., Downing, J. A., Cotner, J. B., Loiselle, S. A., Striegl, R. G., Ballatore, T. J., Dillon, P., Finlay, K., Fortino, K., Knoll, L. B., Kortelainen, P. L., Kutser, T., Larsen, S., Laurion, I., Leech, D. M., McCallister, S. L., McKnight, D. M., Melack, J. M., Overholt, E., Porter, J. A., Prairie, Y., Renwick, W. H., Roland, F., Sherman, B. S., Schindler, D. W., Sobek, S., Tremblay, A., Vanni, M. J., Verschoor, A. M., von Wachenfeldt, E., and Weyhenmeyer, G. A.: Lakes and reservoirs as regulators of carbon cycling and climate, Limnol. Oceanogr., 54, 2298-2314, doi:10.4319/lo.2009.54.6_part_2.2298, 2009.

Vachon, D., Prairie, Y. T., and Cole, J. J.: The relationship between near-surface turbulence and gas transfer velocity in freshwater systems and its implications for floating chamber measurements of gas exchange, Limnol. Oceanogr., 55, 1723-1732, doi:10.4319/lo.2010.55.4.1723, 2010.

Wallin, M. B., Oquist, M. G., Buffam, I., Billett, M. F., Nisell, J., and Bishop, K. H.: Spatiotemporal variability of the gas transfer coefficient $\left(K\left(\mathrm{CO}_{2}\right)\right)$ in boreal streams: implications for large scale estimates of $\mathrm{CO}_{2}$ evasion, Global Biogeochem. Cy., 25, GB3025, doi:10.1029/2010gb003975, 2011. 